\title{
C-Reactive Protein as a Marker of Postoperative Complication of Emergency Colorectal Surgery
}

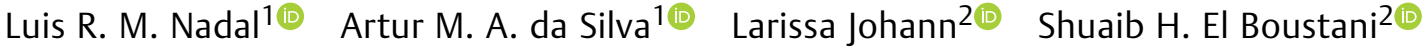 \\ Maria Beatriz A. S. Medrado ${ }^{1 \odot}$ Jose F. M. Farah ${ }^{1 \odot}$ Renato A. Lupinacci ${ }^{1 \odot}$ \\ ${ }^{1}$ General and Oncologic Surgery Service, Hospital do Servidor Público \\ Estadual, São Paulo, São Paulo, Brazil \\ 2 Medicine Student, Faculdade de Medicina, Universidade Cidade de \\ Address for correspondence Luis R. M. Nadal, MD, MSc, Rua Mateus \\ Grou, 130, São Paulo - SP, CEP: 05415-040, Brazil \\ (e-mail: luis.nadal@einstein.br).
} São Paulo, São Paulo, São Paulo, Brazil

J Coloproctol 2021;41(4):375-382.

\begin{abstract}
Introduction The literature converges regarding the use of C-reactive protein (CRP) tests between postoperative days (PODs) 3 and 5 of elective procedures. In this period, they have great sensitivity and negative predictive value (NPV) for severe and anastomotic complications about two days before the first clinical sign. The few studies on colorectal urgency suggest that, despite the different initial values according to the surgical indication, following POD 3, the level of CRP is similar to that of elective procedures. However, given the heterogeneity of the studies, there is no consensus on the cutoff values for this use.

Objective To validate the use and propose a PO CRP cut-off value in urgent colorectal procedures as an exclusion criterion for complications of anastomosis or the abdominal cavity.

Method Retrospective analysis of the medical records of 308 patients who under-

Keywords

- colorectal surgery

- C-reactive protein

- postoperative complications

- acute surgery went urgent colorectal surgical procedures between January 2017 and December 2019. The following data were considered: age, gender, surgical indication, type of procedure performed, complications, CRP levels preoperatively and from POD 1 to 4 , and the severity of the complications. We compared the CRP levels and the percentage variations between the preoperative period and PODs 1 to 4 as markers of severe complications using the receiver operating characteristic (ROC) curve.
\end{abstract}

In this manuscript, we show the use of C-reactive protein (CRP) as a tool to exclude severe postoperative complications of urgent colon and rectal surgery, allowing a safe early discharge, as it is currently used in elective procedures. To our knowledge, this is the first study concerning a formal cut-off for CRP and this use of CRP variation in emergency colorectal surgery.

\section{Introduction}

Colorectal surgical procedures have a high incidence of complications, reaching up to $65 \%{ }^{1}$ Although these procedures are frequently performed, there are reports of up to $20 \%$ of anastomotic leaks when they are performed elective$1 y,{ }^{2,3}$ with a mortality of $\sim 22 \%$ for this diagnosis. ${ }^{2,4}$ However, $\sim 30 \%$ of colorectal operations are performed as a matter of received

January 20, 2021

accepted after revision

June 15, 2021
DOI https://doi.org/

10.1055/s-0041-1736641. ISSN 2237-9363. (c) 2021. Sociedade Brasileira de Coloproctologia. All rights reserved.

This is an open access article published by Thieme under the terms of the Creative Commons Attribution-NonDerivative-NonCommercial-License, permitting copying and reproduction so long as the original work is given appropriate credit. Contents may not be used for commercial purposes, or adapted, remixed, transformed or built upon. (https://creativecommons.org/ licenses/by-nc-nd/4.0/)

Thieme Revinter Publicações Ltda., Rua do Matoso 170, Rio de Janeiro, RJ, CEP 20270-135, Brazil 
Results The levels of CRP on POD4, and their percentage drops between PODs 2 to 4 and PODs 3 to 4 , were better to predict severe complications. A cutoff of $7.45 \mathrm{mg} / \mathrm{dL}$ on POD 4 had $91.7 \%$ of sensitivity and NPV. A 50\% drop between PODs 3 and 4 had $100 \%$ of sensitivity and NPV.

Conclusion Determining the level of CRP is useful to exclude severe complications, and it could be a criterion for hospital discharge in POD 4 of emergency colorectal surgery.

urgency, ${ }^{5}$ and, in this condition, the overall mortality reaches around $25 \%{ }^{6}$

In the last decade, there has been an increase in the number of studies aimed at reducing the impact of surgical complications. Measures for the optimization of interventions in the postoperative (PO) period and the detection of complications before the onset of clinical manifestations have helped reduce the severity of complications, the length of the hospital stay, and mortality. ${ }^{2}$ For this purpose, the use of serum inflammatory markers is already well established.

The most commonly used inflammation marker is Creactive protein (CRP). It is synthesized by hepatocytes as part of the acute phase response after stimulation by interleukin-6 (IL-6), tumor necrosis factor- $\alpha$ (TNF- $\alpha$ ), and IL-1 $\beta$ originated from the site of inflammation. C-reactive protein is a valuable marker to detect disease activity, inflammatory response, and PO recovery due to its short half-life (19 hours). ${ }^{2}$

The literature converges regarding the use of CRP tests between postoperative days (PODs) 3 and 5 of elective procedures. In this period, there is great sensitivity and negative predictive value (NPV) for severe and anastomotic complications about two days before the first clinical sign. ${ }^{7}$ The few studies on colorectal urgency suggest that despite the different initial values according to the surgical indication, following POD 3, the level of CRP is similar to that of elective procedures. ${ }^{8}$

A recent review ${ }^{9}$ validated the value of $10 \mathrm{mg} / \mathrm{dL}$ as a safe level for hospital discharge in POD 4 free of any complications of the surgical act, regardless of whether it is urgent or elective. However, given the heterogeneity of published studies, there is no consensus on the cutoff values for this use. Similarly, we found a single study ${ }^{10}$ using the variation in CRP levels as a prognostic factor in the PO period, but the procedure evaluated was gastrectomy, and, as far as we know, there is no publication with this assessment in colorectal emergency surgery. Thus, the present study aimed to validate the use and propose a PO CRP cut-off value in urgent colorectal procedures as an exclusion criterion for complications of anastomosis or the abdominal cavity.

\section{Methods}

A retrospective analysis of the medical records of patients older than 18 years of age submitted to urgent colorectal surgical between January 2017 and December 2019 by the General and Oncologic Surgery Service of Hospital do Servi- dor Publico Estadual - Francisco Morato de Oliveira, in São Paulo, Brazil.

The procedures considered were performed with broad access to the abdominal cavity by both laparotomy and laparoscopy, followed by decompressive ostomies or colorectal resections, excluding appendectomy for the persent analysis.

We assessed the following data: gender, age, surgical indication, type of procedure, PO complication, preoperative, and PO CRP levels from PODs 1 to 4 . We stratified the severity of PO complications based on the Clavien-Dindo classification, ${ }^{11}$ and considered Clavien-Dindo I and II mild complications, and III and IV, severe complications. Surgical-site infections (SSIs) were defined according to the guideline of the Centers for Disease Control and Prevention (CDC). ${ }^{12}$

We compared the median CRP level between PODs 1 to 4 , as well as the percentage of variation between these days when infection and anastomotic complications were present.

\section{Statistics}

The continuous variables were expressed as means \pm standard deviations or medians with interquartile ranges. The means were compared by the Student $t$-test or the MannWhitney, test according to the distribution. The qualitative variables were expressed as percentages and compared with the Chi-Squared or Fisher exact tests, when the expected value was lower than 5 . We used the receiver operating characteristic (ROC) curve for CRP dosages and the percentage variation between subsequent PODs, setting the best areas under the curve (AUCs) to predict severe complications and deaths, and for intra-abdominal infections characterized as intracavitary abscesses, anastomotic leaks, or stoma collapses. For the best AUC, we then used the ROC individually to calculate the cutoff values for better sensitivity and NPV.

The threshold for statistical significance was established as $p<0.05$ for all analyses. The data were analyzed using the Statistical Package for the Social Sciences (IBM SPSS Statistics for Windows, IBM Corp., Armonk, NY, US) software, version 23.0.

\section{Results}

We assessed the medical records of 308 patients (-Table $\mathbf{1}$ ), with a mean age of $70.3 \pm 12.65$ years, $45.1 \%$ of whom were male. A total of 176 patients (57.1\%) underwent surgery for 
C-Reactive Protein as a Marker of Postoperative Complication of Emergency Colorectal Surgery Nadal et al. 377

Table 1 Characteristics of the study sample

\begin{tabular}{|c|c|c|c|c|c|c|c|}
\hline \multirow[b]{2}{*}{ Gender } & \multicolumn{2}{|c|}{ Neoplasia } & \multicolumn{2}{|c|}{ Benign disease } & \multicolumn{2}{|l|}{ Total } & \multirow[t]{2}{*}{$p$-value } \\
\hline & & & & & & & \\
\hline Male - n (\%) & 81 & $(46.0 \%)$ & 58 & $(43.9 \%)$ & 139 & $(45.1 \%)$ & \multirow[t]{2}{*}{0.716} \\
\hline Female - n (\%) & 95 & $(54.0 \%)$ & 74 & $(56.1 \%)$ & 169 & $(54.9 \%)$ & \\
\hline \multicolumn{8}{|l|}{ Age (years) } \\
\hline Average & 70.3 & \pm 14.82 & 70.3 & \pm 0.11 & 70.3 & \pm 12.65 & 0.999 \\
\hline \multicolumn{8}{|l|}{ Indication } \\
\hline Inflammation/Infection - n (\%) & 30 & $(17.0 \%)$ & 36 & $(27.3 \%)$ & 66 & $(21.4 \%)$ & \multirow[t]{5}{*}{$<0.001$} \\
\hline Obstruction - n (\%) & 124 & $(70.5 \%)$ & 42 & $(31.8 \%)$ & 166 & $(53.9 \%)$ & \\
\hline Ischemia - n (\%) & 0 & $(0.0 \%)$ & 13 & $(9.8 \%)$ & 13 & $(4.2 \%)$ & \\
\hline Bleeding - n (\%) & 5 & $(2.8 \%)$ & 4 & $(3.0 \%)$ & 9 & $(2.9 \%)$ & \\
\hline Perforation - n (\%) & 17 & $(9.7 \%)$ & 37 & $(28.0 \%)$ & 54 & $(17.5 \%)$ & \\
\hline \multicolumn{8}{|l|}{ Procedure } \\
\hline Right colectomy - n (\%) & 77 & $(43.8 \%)$ & 55 & $(41.7 \%)$ & 132 & $(42.9 \%)$ & \multirow[t]{7}{*}{0.850} \\
\hline Transverse colectomy - n (\%) & 3 & $(1.7 \%)$ & 3 & $(2.3 \%)$ & 6 & $(1.9 \%)$ & \\
\hline Left colectomy - n (\%) & 20 & $(11.4 \%)$ & 13 & $(9.8 \%)$ & 33 & $(10.7 \%)$ & \\
\hline Right + left colectomy - n (\%) & 4 & $(2.3 \%)$ & 1 & $(0.8 \%)$ & 5 & $(1.6 \%)$ & \\
\hline Total colectomy - n (\%) & 15 & $(8.5 \%)$ & 9 & $(6.8 \%)$ & 24 & $(7.8 \%)$ & \\
\hline Anterior resection - n (\%) & 54 & $(30.7 \%)$ & 49 & $(37.1 \%)$ & 103 & $(33.4 \%)$ & \\
\hline Loop ostomy - n (\%) & 3 & $(1.7 \%)$ & 2 & $(1.5 \%)$ & 5 & $(1.6 \%)$ & \\
\hline Primary anastomosis - n (\%) & 66 & $(37.5 \%)$ & 44 & $(33.3 \%)$ & 110 & $(35.7 \%)$ & 0.418 \\
\hline \multicolumn{8}{|l|}{ Complications } \\
\hline None - n (\%) & 13 & $(7.4 \%)$ & 5 & $(3.8 \%)$ & 18 & $(5.8 \%)$ & \multirow[t]{6}{*}{0.006} \\
\hline Clavien-Dindo I - n (\%) & 16 & $(9.1 \%)$ & 9 & $(6.8 \%)$ & 25 & $(8.1 \%)$ & \\
\hline Clavien-Dindo II - n (\%) & 80 & $(45.4 \%)$ & 35 & $(26.5 \%)$ & 115 & $(37.3 \%)$ & \\
\hline Clavien-Dindo III - n (\%) & 14 & $(8.0 \%)$ & 8 & $(6.1 \%)$ & 22 & $(7.1 \%)$ & \\
\hline Clavien-Dindo IV - n (\%) & 19 & $(10.8 \%)$ & 25 & $(18.9 \%)$ & 44 & $(14.3 \%)$ & \\
\hline Clavien-Dindo V - n (\%) & 34 & $(19.3 \%)$ & 50 & $(37.9 \%)$ & 84 & $(27.3 \%)$ & \\
\hline Abdominal complications - n (\%) & 24 & $(13.6 \%)$ & 18 & $(13.6 \%)$ & 42 & $(13.6 \%)$ & $>0.999$ \\
\hline Infectious complications - n (\%) & 66 & $(37.5 \%)$ & 74 & $(56.1 \%)$ & 140 & $(45.5 \%)$ & 0.001 \\
\hline \multicolumn{8}{|l|}{ Surgical-site infections } \\
\hline Superficial incisional - n (\%) & 19 & $(10.8 \%)$ & 16 & $(12.1 \%)$ & 35 & $(11.4 \%)$ & 0.717 \\
\hline Deep Incisional - n (\%) & 35 & $(19.9 \%)$ & 43 & $(32.6 \%)$ & 78 & $(25.3 \%)$ & 0.011 \\
\hline Organ/space - n (\%) & 42 & $(23.9 \%)$ & 51 & $(38.6 \%)$ & 93 & $(30.2 \%)$ & 0.005 \\
\hline Distance - n (\%) & 32 & $(18.2 \%)$ & 46 & $(34.8 \%)$ & 78 & $(25.3 \%)$ & 0.001 \\
\hline Noninfectious complications - n (\%) & 77 & $(43.8 \%)$ & 77 & $(58.3 \%)$ & 154 & $(50.0 \%)$ & 0.011 \\
\hline \multicolumn{8}{|l|}{ Length of stay (days) } \\
\hline Average & 13.7 & \pm 17.46 & 15.68 & \pm 16.78 & 14.58 & \pm 17.17 & 0.332 \\
\hline Median & 8.0 & & 10.00 & & 8.0 & & \\
\hline Total - n (\%) & 176 & (57.1\%) & 132 & $(42.9 \%)$ & 308 & $(100.0 \%)$ & \\
\hline
\end{tabular}

neoplastic urgencies, with no difference between genders $(p=0.716)$.

The main surgical indication was colon obstruction (53.9\%), followed by inflammation (21.4\%) and perforation
(17.5\%). All indications had different frequencies between the groups $(p<0,001)$ : the neoplastic group had more cases of obstruction (70.5\%), but fewer cases of inflammation, ischemia, and perforation. An equal percentage for all groups 
Table 2 Postoperative complications of the study sample

\begin{tabular}{|l|l|l|l|l|l|l|l|l|}
\hline Complication & \multicolumn{2}{l|}{ Uncomplicated } & \multicolumn{2}{l|}{ Mild } & \multicolumn{2}{l|}{ Severe } & \multicolumn{2}{l|}{ Death } \\
\hline Inflammation/infection - n (\%) & 6 & $(9.1 \%)$ & 31 & $(47.0 \%)$ & 14 & $(21.2 \%)$ & 15 & $(22.7 \%)$ \\
\hline Obstruction - n (\%) & 8 & $(4.8 \%)$ & 95 & $(57.2 \%)$ & 28 & $(16.9 \%)$ & 35 & $(21.1 \%)$ \\
\hline Ischemia - n (\%) & 1 & $(7.7 \%)$ & 0 & $(0.0 \%)$ & 4 & $(30.8 \%)$ & 8 & $(61.5 \%)$ \\
\hline Bleeding - n (\%) & 2 & $(22.2 \%)$ & 1 & $(11.1 \%)$ & 2 & $(22.2 \%)$ & 4 & $(44.4 \%)$ \\
\hline Perforation - n (\%) & 1 & $(1.9 \%)$ & 13 & $(24.1 \%)$ & 18 & $(33.3 \%)$ & 22 & $(40.7 \%)$ \\
\hline Total - n (\%) & 18 & $(5.8 \%)$ & 140 & $(45.5 \%)$ & 66 & $(21.4 \%)$ & 84 & $(27.3 \%)$ \\
\hline
\end{tabular}

was only observed in the Bonferroni post-hoc test for colorectal bleeding ( - Table 1 ). Among the procedures, regardless of the etiological group $(p=0.850)$, the most performed were right colectomy (42.9\%) and anterior resection (33.4\%). Anastomosis was performed in 110 patients (35.7\%).

We observed a total of $51.3 \%$ of absent or mild complications, with the Bonferroni test showing that patients operated due to neoplastic disease had a greater number of Clavien-II complications (45.4\% versus $26.5 \%$ ) and lower mortality (19.3\% versus $37.9 \%$ ). There was a greater severity of PO complications among patients operated due to diseases of benign etiology $(p=0.006)$. The overall mortality was of $27.3 \%$, with $10 \%$ of cases of colonic ischemia (-Table 2).
The analysis of the CRP values for anastomotic/abdominal complications (-Figs. 1 and 2 ) showed a better AUC (0.744) for the variation between PODs 2 to 4 . For this period, an $83.5 \%$ drop had $100 \%$ of sensitivity and NPV. The variation between PODs 3 to 4 (AUC = 0.695) had, for a 50\% drop, $96.9 \%$ of sensitivity and an NPV of $94.7 \%$.

The CRP values that provided the highest accuracy to exclude severe complications (-Figs. 3 and $\mathbf{4}$ ) were those obtained for POD4 (AUC $=0.691$ ) and the percentage variation between PODs 3to 4 (AUC = 0.702). Between PODs 3 to 4, a $50 \%$ drop in CRP levels had a sensitivity of $94 \%$, with a specificity of $15.3 \%$, and an NPV of $73.7 \%$.

The cut-off value on POD 4 for $100 \%$ of sensitivity and NPV was of $2.83 \mathrm{mg} / \mathrm{dL}$ for both anastomotic/abdominal and

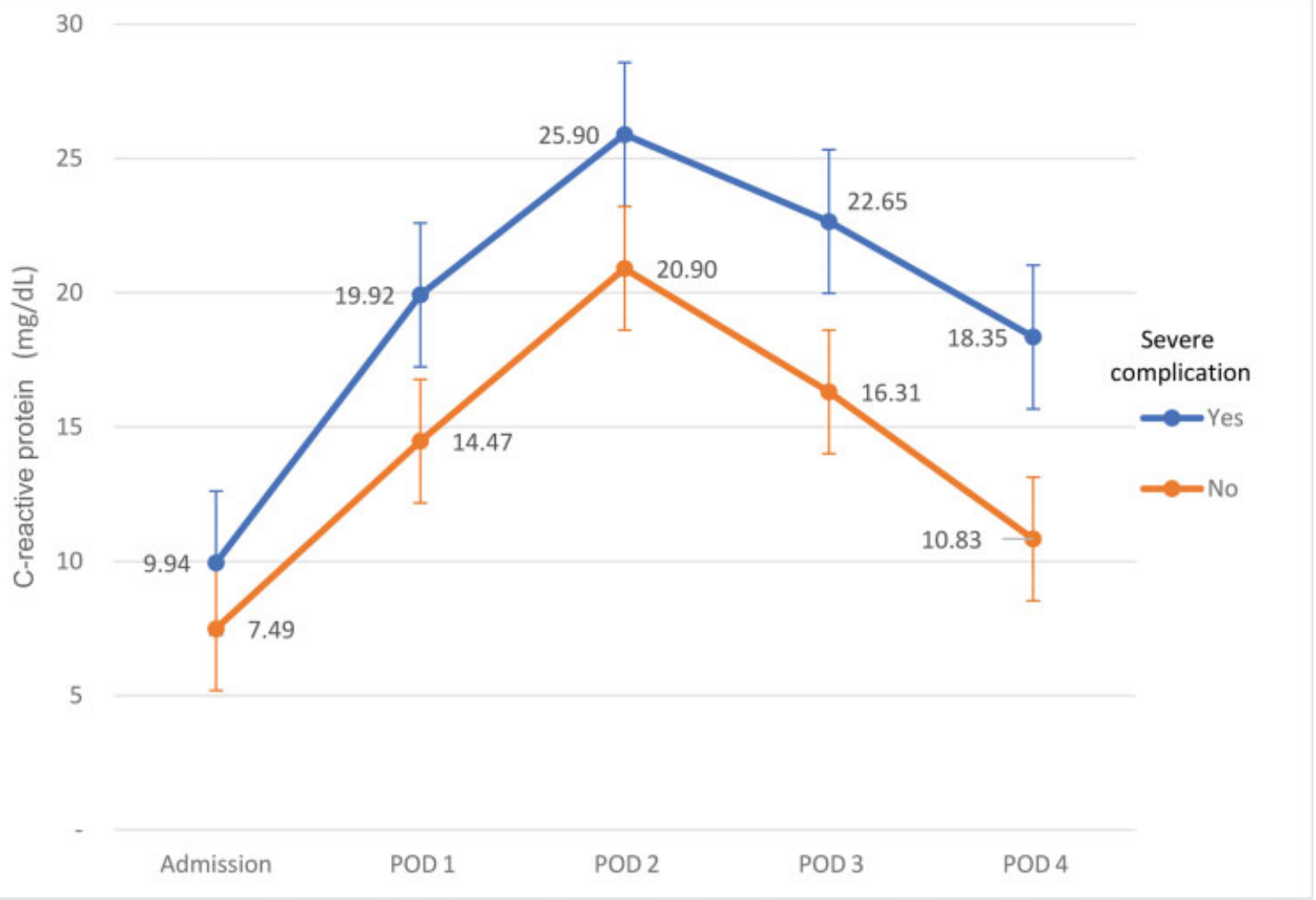

Fig. 1 Median CRP (C-reactive protein( levels ( $\mathrm{mg} / \mathrm{dL}$ ), with standard error, in patients that had severe intra-abdominal postoperative complication and patients with mild or no complications between the preoperative period and the fourth postoperative day (POD 4). 


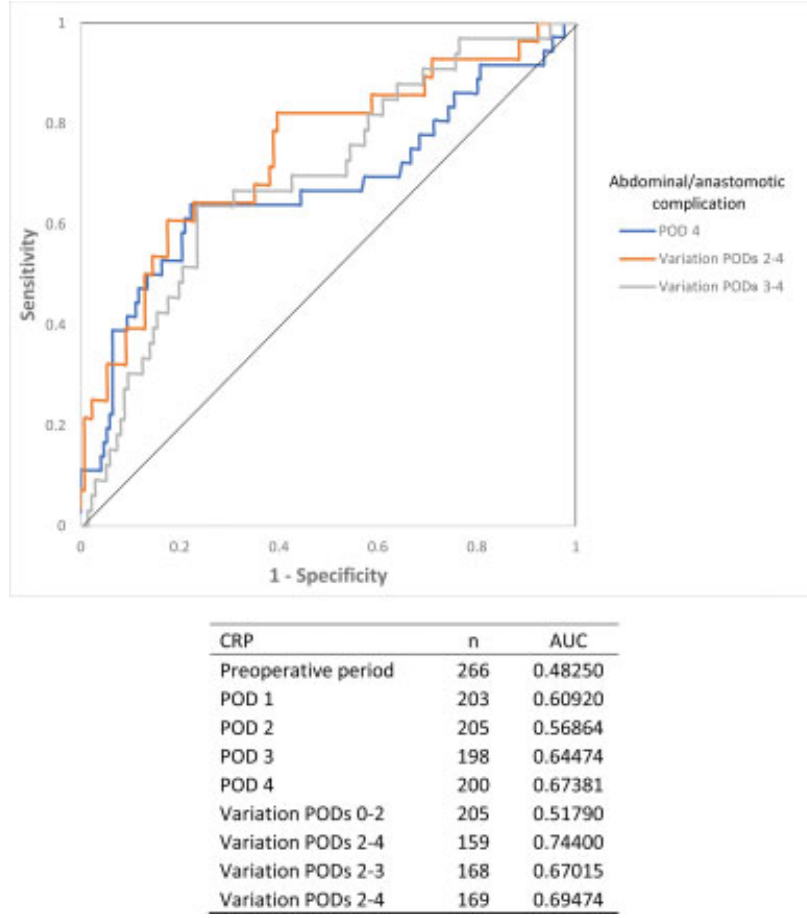

Fig. 2 Receiver operating characteristic curve for the accuracy of Creactive protein (CRP) between admission and the fourth postoperative day (POD 4), and the percentage variation between these dosages in the diagnosis of complications of anastomosis/ostomy and the abdominal cavity. Abbreviation: AUC, area under the curve.

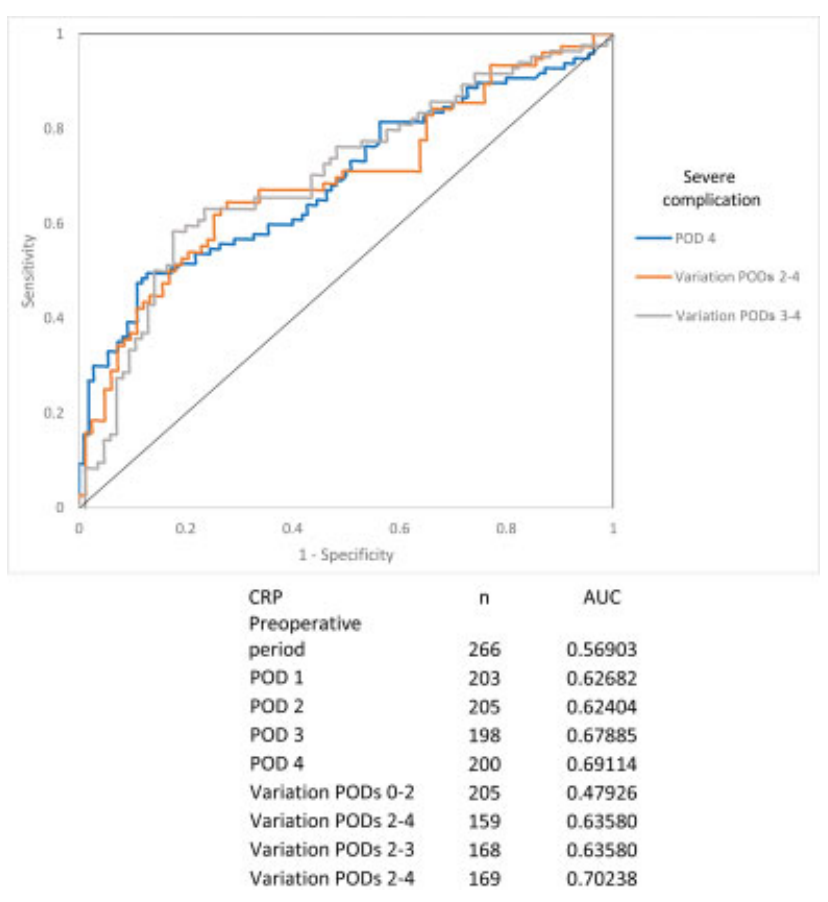

Fig. 4 Receiver operating characteristic curve for the accuracy of Creactive protein (CRP) between admission and the fourth postoperative day (POD 4) and the percentage variation between these dosages in the diagnosis of severe complications. Abbreviation: AUC, area under the curve.

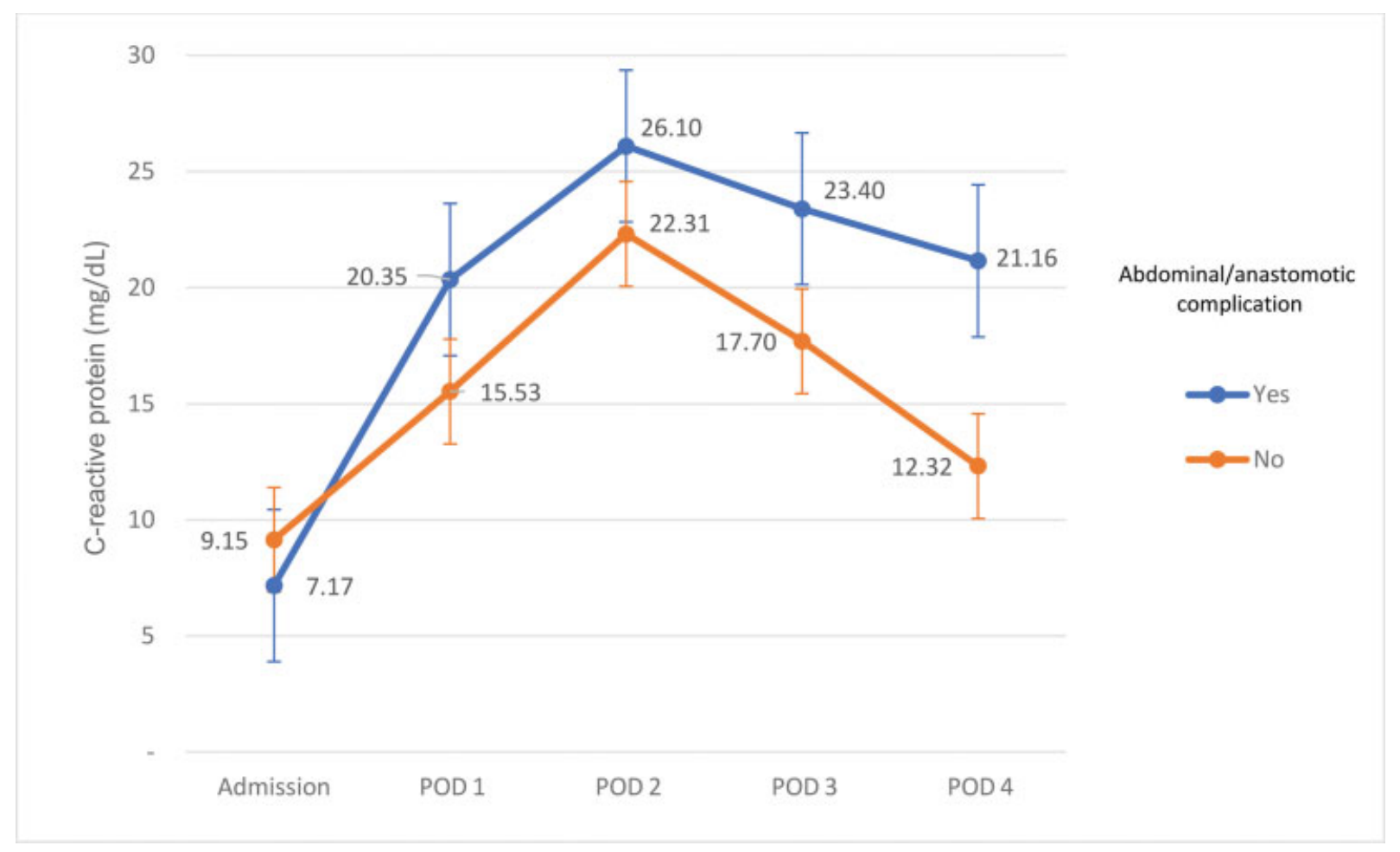

Fig. 3 Median CRP (C-reactive protein) levels ( $\mathrm{mg} / \mathrm{dL}$ ), with standard error, in patients that had intra-abdominal postoperative complication and patients with no intra-abdominal complications between the preoperative and the fourth postoperative day (POD 4). 
severe complications. We determined a CRP of $7.48 \mathrm{mg} / \mathrm{dL}$ considering sensitivities of $91.7 \%$ for abdominal complications, and of $89.7 \%$ for severe complications, with NPVs of $91.7 \%$ and $73 \%$ respectively.

\section{Discussion}

In the present study, we were able to propose a useful cut-off value on POD 4, and associate a CRP drop compatible with its short half-life to the absence of severe and anastomotic/abdominal complications. When comparing all values in the ROC curve, the CRP on POD4 showed a higher AUC. When we individualized their cut-off values, however, the levels evidenced for maximum sensitivity and NPV were of $2.83 \mathrm{mg} / \mathrm{dL}$, a very low and infrequent finding. Only four patients in the sample met this criterion, all with Clavien-Dindo II complications and no infection. However, following the rationale for the 19-hour half-life of CRP, we found that a 51\% CRP drop between PODs 2 and 3 and a $46 \%$ drop between PODs 3 and 4 showed $100 \%$ of sensitivity and NPV for anastomotic leak and abdominal cavity abscess. We have not heard of another study so far using the percentage variation of CRP between PODs of colorectal operations, be them elective or urgent, to predict complications, or as a criterion for hospital discharge.

The use of inflammatory markers, especially CRP, has enabled safe early hospital discharge for patients undergoing elective colorectal procedures with a lower chance of readmission, ${ }^{13}$ and the diagnosis of complications before their first clinical manifestation. ${ }^{2,14}$ Thus, reductions in the severity of complications, length of hospital stay, and mortality are expected. $^{15}$

The serum values of CRP tend to be low in healthy individuals. ${ }^{15,16}$ Due to the metabolic response to surgical trauma, the release of inflammatory cytokines promotes the elevation of CRP levels up to POD The trend towards a complication-free course is a peak in serum CRP on POD 2 followed by a continuous drop on subsequent days. The higher levels of preoperative CRP in emergency surgery patients used to be a criterion to exclude this population from studies on inflammatory markers in the PO period. However, Straatman et al. ${ }^{8}$ demonstrated that, despite that variation, the CRP levels stabilized starting on POD 3, as in elective cases.

Patients with poor outcomes are more likely to have high CRP levels even in the first 24 PO hours, and a drop in this indicator was associated with a lower complication rate. ${ }^{15,17,18}$ This finding has been corroborated by most studies since the beginning of the use of CRP in the PO of surgical procedures in general, ${ }^{19,20}$ and, more recently, specifically in the case of colorectal resections. ${ }^{8}$ We observed the same high CRP levels in the preoperative period or on POD 1 (-Fig.5), but the values were not useful for closer follow-up, for lowering the threshold for intervention, or for making

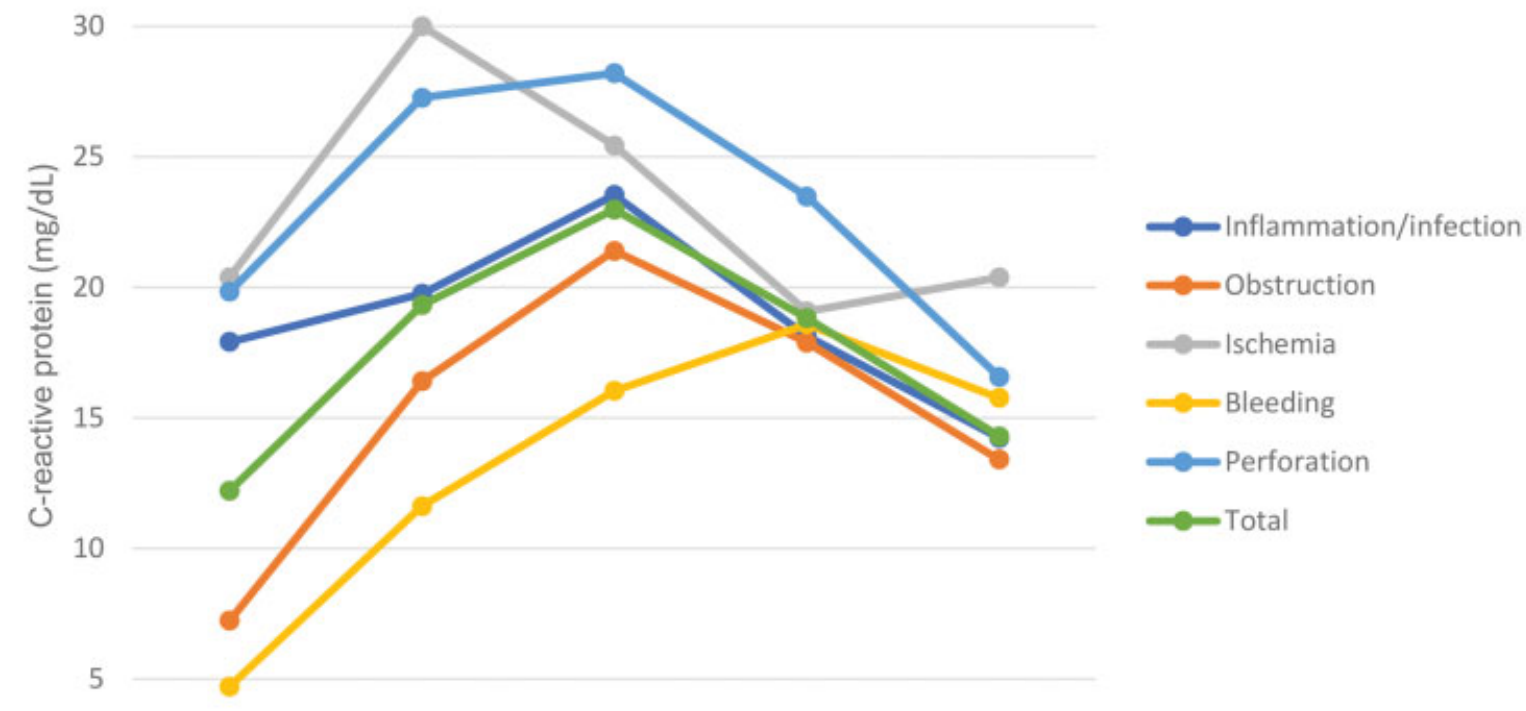

0

$\begin{array}{lllll}\text { Admission } & \text { POD } 1 & \text { POD } 2 & \text { POD } 3 & \text { POD } 4\end{array}$

Fig. 5 Evolution of the mean dosages of C-reactive protein according to the surgical indication between the preoperative period and the fourth postoperative day (POD 4). 
radiology-based tests mandatory in the initial PO for early diagnosis of severe or anastomotic complications.

The study groups were thus stratified considering the different characteristics of indication for urgent surgery of patients with neoplastic and non-neoplastic ("benign") disease, as well as the greater possibility of prevention of cases of advanced tumors. Our service is in the only hospital of a health insurance company for $\sim 1.5$ million public servants and their dependents in the state of São Paulo, most of them elderly. This survey of the total neoplastic emergencies composes a study recognizing our patterns for establishing prevention plans. Our sample had a higher frequency of obstruction for neoplasms (124 of $176 ; 70.5 \%$ ), while nonneoplastic indications included mostly (86 of $132 ; 65,1 \%$ ) etiologies with higher tissue and inflammation such as acute diverticulitis with peritonitis and acute colonic ischemia.

The higher incidence of death among patients without neoplasia might be due to the inclusion in this group of diseases of vascular and perforative etiology, with mortality rates of $61.5 \%$ and $40.7 \%$ respectively. Despite its rate, mortality in the present study was equivalent to the mortality reported in the literature: 26 to $81 \%$ for acute mesenteric ischemia, $^{21}$ and 30 to $70 \%$ for perforations. ${ }^{22}$

Preoperative CRP values may vary even in elective patients, as well as the inflammatory PO response of each individual due to differences in immune response associated with age, gender, race, and nutrition status. ${ }^{10}$ It seems more reliable to use the variation than an isolated value. Since CRP has a 19-hour half-life, when there is no stimulus for its production, there is a significant drop in levels from one day to the next. 23

The present study is limited by its retrospective design. Moreover, we did not consider the comorbidities of patients and preoperative clinical conditions or demographic data, as in most publications.

We suggest daily CRP tests from POD 2 onwards for the use of its gradient as a criterion for hospital discharge on PODs 3 or 4 of colorectal surgical procedures as a matter of urgency.

\section{Conclusion}

The levels of CRP can be used for the exclusion of severe complications and as a criterion for hospital discharge on POD 4 of emergency colorectal surgery.

Conflict of Interests

The authors have no conflict of interests to declare.

\section{Acknowledgments}

The authors would like to thank Helena Passarelli Giroud Joaquim and Sidney Roberto Nadal, for their critical review of the manuscript.

\section{References}

1 European Society of Coloproctology collaborating group (2017) Relationship between method of anastomosis and anastomotic failure after right hemicolectomy and ileo-caecal resection: an international snapshot audit. Colorectal Dis 2015;19:e296-e311. Doi: $10.1111 /$ codi.13646

2 Welsch T, Müller SA, Ulrich A, et al. C-reactive protein as early predictor for infectious postoperative complications in rectal surgery. Int J Colorectal Dis 2007;22(12):1499-1507. Doi: 10.1007/s00384-007-0354-3

3 Straatman J, Cuesta MA, Gisbertz SS, Van der Peet DL. Value of a step-up diagnosis plan: CRP and CT-scan to diagnose and manage postoperative complications after major abdominal surgery. Rev Esp Enferm Dig 2014;106(08):515-521

4 Alberts JCJ, Parvaiz A, Moran BJ. Predicting risk and diminishing the consequences of anastomotic dehiscence following rectal resection. Colorectal Dis 2003;5(05):478-482. Doi: 10.1046/ j.1463-1318.2003.00515.x

5 Lohsiriwat V, Jitmungngan R. Enhanced recovery after surgery in emergency colorectal surgery: Review of literature and current practices. World J Gastrointest Surg 2019;11(02):41-52. Doi: 10.4240/wjgs.v11.i2.41

6 Biondo S, Kreisler E, Millan M, et al. Impact of surgical specialization on emergency colorectal surgery outcomes. Arch Surg 2010; 145(01):79-86. Doi: 10.1001/archsurg.2009.208

7 Adamina M, Warschkow R, Näf F, et al. Monitoring c-reactive protein after laparoscopic colorectal surgery excludes infectious complications and allows for safe and early discharge. Surg Endosc 2014;28(10):2939-2948. Doi: 10.1007/s00464-0143556-0

8 Straatman J, de Weerdesteijn EW, Tuynman JB, Cuesta MA, van der Peet DL. C-Reactive Protein as a Marker for Postoperative Complications. Are There Differences in Emergency and Elective Colorectal Surgery? Dis Colon Rectum 2016;59(01):35-41. Doi: 10.1097/DCR.0000000000000506

9 Benoit O, Faron M, Margot N, Creavin B, Debove C, Tiret E, Parc Y, Lefevre JH. C-Reactive Protein Values After Colorectal Resection: Can We Discharge a Patient With a C-Reactive Protein Value $>100$ ? A Retrospective Cohort Study. Dis Colon Rectum 2019 Jan;62(1):88-96. doi: 10.1097/DCR.0000000000001216. PMID: 30451748

10 Lee S-H, Kim KH, Choi CW, et al. Reduction rate of C-reactive protein as an early predictor of postoperative complications and a reliable discharge indicator after gastrectomy for gastric cancer. Ann Surg Treat Res 2019;97(02):65-73. Doi: 10.4174/ astr.2019.97.2.65

11 Dindo D, Demartines N, Clavien PA. Classification of surgical complications: a new proposal with evaluation in a cohort of 6336 patients and results of a survey. Ann Surg 2004;240(02): 205-213

12 Berríos-Torres SI, Umscheid CA, Bratzler DW, et al; Healthcare Infection Control Practices Advisory Committee. Centers for disease control and prevention guideline for the prevention of surgical site infection, 2017. JAMA Surg 2017;152(08):784-791. Doi: 10.1001/jamasurg.2017.0904

13 Pantel HJ, Jasak LJ, Ricciardi R, et al. Should they stay or should they go? the utility of $\mathrm{C}$-reactive protein in predicting readmission and anastomotic leak after colorectal resection. Dis Colon Rectum 2019;62(02):241-247. Doi: 10.1097/DCR.0000000000001225

14 Warschkow R, Beutner U, Steffen T, et al. Safe and early discharge after colorectal surgery due to C-reactive protein: a diagnostic meta-analysis of 1832 patients. Ann Surg 2012;256(02):245-250. Doi: $10.1097 /$ SLA.0b013e31825b60f0

15 Crockson RA, Payne CJ, Ratcliff AP, Soothill JF. Time sequence of acute phase reactive proteins following surgical trauma. Clin Chim Acta 1966;14(04):435-441. Doi: 10.1016/0009-8981(66) 90030-1

16 Straatman J, Harmsen AMKK, Cuesta MA, Berkhof J, Jansma EP, van der Peet DL. Predictive Value of C-Reactive Protein for Major Complications after Major Abdominal Surgery: A Systematic Review and Pooled-Analysis. PLoS One 2015;10(07):e0132995. Doi: $10.1371 /$ journal.pone.0132995 
382 C-Reactive Protein as a Marker of Postoperative Complication of Emergency Colorectal Surgery Nadal et al.

17 Fischer CL, Gill C, Forrester MG, Nakamura R. Quantitation of "acute-phase proteins" postoperatively. Value in detection and monitoring of complications. Am J Clin Pathol 1976;66(05): 840-846. Doi: 10.1093/ajcp/66.5.840

18 Mustard RA Jr, Bohnen JM, Haseeb S, Kasina R. C-reactive protein levels predict postoperative septic complications. Arch Surg 1987; 122(01):69-73. Doi: 10.1001/archsurg.1987.01400130075011

19 Ortega-Deballon P, Radais F, Facy O, et al. C-reactive protein is an early predictor of septic complications after elective colorectal surgery. World J Surg 2010;34(04):808-814. Doi: 10.1007/ s00268-009-0367-x

20 Warschkow R, Tarantino I, Torzewski M, Näf F, Lange J, Steffen T. Diagnostic accuracy of C-reactive protein and white blood cell counts in the early detection of inflammatory complications after open resection of colorectal cancer: a retrospective study of 1,187 patients. Int J Colorectal Dis 2011;26(11):1405-1413. Doi: 10.1007/s00384-011-1262-0

21 Ehlert BA. Acute Gut Ischemia. Surg Clin North Am 2018;98(05): 995-1004. Doi: 10.1016/j.suc.2018.06.002

22 Shin R, Lee SM, Sohn B, et al. Predictors of Morbidity and Mortality After Surgery for Intestinal Perforation. Ann Coloproctol 2016;32 (06):221-227. Doi: 10.3393/ac.2016.32.6.221

23 Ridker PM. Clinical application of C-reactive protein for cardiovascular disease detection and prevention. Circulation 2003;107(03):363-369. Doi: 10.1161/01.CIR.0000053730. $47739.3 \mathrm{C}$ 